\title{
WILEY-VCH
}

DOI: 10.1002/ ((please add manuscript number))

Full Paper

\section{Real Time Investigation of Intercalation and Structure Evolution in Printed Polymer:Fullerene Bulk Hetero-Junction Thin Films}

Thaer Kassar, Nusret S. Güldal, Marvin Berlinghof, Tayebeh Ameri, Andreas Kratzer, Bob C. Schroeder, Giovanni Li Destri, Andreas Hirsch, Martin Heeney, Iain McCulloch, Christoph J. Brabec, and Tobias Unruh*

T. Kassar, M. Berlinghof, Prof. T. Unruh

Friedrich-Alexander-Universität Erlangen-Nürnberg

Chair of Crystallography and Structure Physics

Staudtstraße 3, 91058 Erlangen, Germany

E-mail: tobias.unruh@fau.de

N.S. Güldal, Dr. T. Ameri, Prof. C.J. Brabec

Friedrich-Alexander-Universität Erlangen-Nürnberg

Chair of Materials for Electronics and Energy Technology

Martensstraße 7, 91058 Erlangen, Germany

A. Kratzer, Prof. A. Hirsch

Friedrich-Alexander-Universität Erlangen-Nürnberg

Interdisciplinary Center of Molecular Materials (ICMM)

Henkestraße 42, 91054 Erlangen, Germany

Dr. B. C. Schroeder, Prof. M. Heeney, Prof. I. McCulloch

Imperial College London

Center for Plastic Electronics

London SW7 2AZ, United Kingdom

Dr. G. Li Destri

The European Synchrotron Radiation Facility (ESRF)

71, Avenue des Martyrs, 38000 Grenoble, France

Keywords: thin films, intercalation dynamics, fullerenes, organic solar cells, grazing incidence diffraction

The complex intermixing morphology is critical for the performance of the nanostructured polymer:fullerene bulk hetero-junction (BHJ) solar cells. Here, time resolved in-situ grazing incidence X-ray diffraction (GIXD) and grazing incidence small angle X-ray scattering (GISAXS) are used to track the structure formation of BHJ thin films formed from the donor polymer Poly(2,5-bis(3-hexadecylthiophen-2-yl)thieno[3,2-b]thiophene) with different fullerene derivative acceptors. The formation of stable bimolecular crystals through the intercalation of fullerene molecules between the side-chains of polymer crystallites is investigated. Such systems exhibit more efficient exciton dissociation but lower photo- 


\section{WILEY-VCH}

conductance and faster decay of charges. On the basis of the experimental observations, intercalation obviously takes place before or with the formation of the crystalline polymer domains. It results in more stable structures whose volume remains constant upon further drying. Three distinct periods of drying are observed and the formation of uni-dimensional fullerene channels along the $\pi$-stacking direction of polymer crystallites is confirmed.

\section{Introduction}

Solution-processable BHJ organic solar cells exhibit a promising potential as inexpensive alternative to traditional inorganic photovoltaics through "roll-to-roll" printing on flexible materials. ${ }^{[1-5]}$ On a laboratory scale devices with power conversion efficiencies exceeding $11 \%$ have been achieved. ${ }^{[4-7]}$ These devices possess an active layer which consists of a blend of an electron-donating conjugated polymer and an electron-accepting fullerene derivative. The polymer is selected to absorb photons in the relevant range of the visible/UV spectrum. In this process, excitons are generated in the polymer. By diffusion, the excitons can reach the donor/acceptor interface at the polymer/fullerene phase boundary where they can dissociate into free charge carriers. Due to the short exciton mean diffusion length of about 5-10 $\mathrm{nm}$ in typical conjugated polymers, ${ }^{[8-9]}$ the two phases need to be intermixed on the nanoscale which ensures an effective charge separation in such BHJ systems. Extraction of photo-generated electrons and holes before recombining requires donor/acceptor percolation pathways to facilitate charge carrier transport. From these considerations, it becomes obvious that the performance of a BHJ solar cell strongly depends on the interpenetrating morphology of the nanostructured active layer. ${ }^{[10-11]}$

BHJs were thought to be separated into domains of relatively pure polymer and pure fullerene phases. ${ }^{[12-15]}$ Later it was found that fullerene derivatives can intercalate between the polymer side chains in some polymer:fullerene blends resulting in bimolecular crystals. Such intercalation affects performance and charge transport of the active layer. ${ }^{[16-17,43]}$ Fullerenes in blends with intercalation fill all the space between the polymer side chains before forming its 


\section{WILEY-VCH}

pure domains. ${ }^{[17]}$ In this case, high fullerene concentrations are needed to achieve interconnected precipitated fullerene domains ${ }^{[18]}$ which are essential for creating electron percolation paths and thus for device operation. ${ }^{[16]}$ Intercalation increases the blend cohesion and resistance to mechanical failure. ${ }^{[19]}$ The bimolecular crystals are thermodynamically stable for fullerene concentrations of approximately one fullerene molecule per monomer. ${ }^{[17]}$ X-ray diffraction can be used to determine whether intercalation occurs in crystalline and semi-crystalline polymer:fullerene blends, respectively. The pBTTT polymer is often used in organic transistors because of its exceptionally high mobilities of holes reaching 1 $\mathrm{cm} 2 / \mathrm{V} / \mathrm{s}^{[23-24]}$ Extensive studies on blends of poly(2,5-bis(3-tetradecylthiophen-2yl)thieno[3,2-b]thiophene) named pBTTT-C14 and the fullerene $\mathrm{PC}_{71} \mathrm{BM}$ or its bisadduct bisPC ${ }_{71} \mathrm{BM}$ have been published with the goal to understand how molecular mixing influences the photovoltaic processes. ${ }^{[20-22]}$ It was found that $\mathrm{PC}_{71} \mathrm{BM}$ intercalation between the side chains of pBTTT severely disrupts the pBTTT packing by inducing bends and twists in the backbone as well as bends in the side chains. ${ }^{[21]}$ The pBTTT:PC ${ }_{71} \mathrm{BM}$ phase diagram was determined using a combination of temperature-dependent 2D GIXD and DSC. ${ }^{[20]}$ Device efficiency was found to be optimal for pBTTT blends with $\mathrm{PC}_{71} \mathrm{BM}$ or $\mathrm{PC}_{60} \mathrm{BM}$ for a mixing ratio of 1:4. In these cases a similar volume of the bimolecular crystals and the pure domains of fullerene is achieved. ${ }^{[1,17,25-26]}$ However, the power conversion efficiencies of pBTTT:PC ${ }_{71} \mathrm{BM}$ systems are less than $3 \%^{[22,27]}$ despite the high mobility of the holes in pBTTT. Photoluminescence (PL) is used to effectively measure the exciton diffusion to a donor-acceptor interface where they can be split into free charges. Excitons in the bimolecular crystals are generated within a few angstroms distance to a donor-acceptor interface and thus almost all of them split into electrons and holes, and the PL signal is completely quenched. ${ }^{[16]}$ It is, however, not surprising that 1:1 $\mathrm{pBTTT}: \mathrm{PC}_{71} \mathrm{BM}$ blends have very low efficiencies of about $0.25 \%$ because most of the fullerene molecules are isolated within the polymer and are not directly connected to the network of fullerene clusters percolating through the active layer. 


\section{WILEY-VCH}

Instead, electrons have to travel along the fullerene channels in the bimolecular crystals to possibly reach a pure fullerene domain. ${ }^{[21,38]}$ The uni-dimensional nature of these channels, which do not necessarily have the same orientation in different crystallites, reduces the effective electron mobility. The 1:4 pBTTT:PC ${ }_{71} \mathrm{BM}$ blends exhibit on the other hand efficiencies up to $2.5 \%$. The still low efficiencies can be attributed to the limitation of photocarrier lifetimes due to the close proximity of the polymer and fullerene in the intercalated phase that increase the probability of charge recombination. ${ }^{[28-33]} \mathrm{A}$ few methods including the adjustment of the fullerene size have recently been applied to inhibit intercalation and allowing for the formation of a continuous electron path already at low fullerene concentrations. Fast cooling rates after annealing 1:1 pBTTT:PC ${ }_{71} \mathrm{BM}$ above the eutectic temperature of $505 \mathrm{~K}$ results in the formation of an electron-conducting $\mathrm{PC}_{71} \mathrm{BM}$ pure phase, but the high temperature results in phase separated domains that are significantly larger than the exciton diffusion length causing poor power conversion efficiency. ${ }^{[20]}$ A combination of mixed-solvent vapor and vapor-assisted imprinting annealing was also performed to induce the aggregation of fullerene which inhibited intercalation behavior, optimized the lateral and vertical phase separation within the active layer and improved the migration of polymer to enhance is crystallinity as well as enhance the photon absorption. ${ }^{[34-35]}$

In this study we aim to analyze the structure formation processes taking place during the formation of a thin active layer upon drying of a doctor-bladed thin liquid film. To our knowledge, this is the first time in situ GIXD and GISAXS are utilized for real-time observations of intercalation dynamics. The results will help to develop better understanding of this process for the sake of the ability to tailor suitable nanostructured BHJ layers in the future.

\section{Methods}

For the study of the structure formation during the drying process of thin photo-active films, a sample cell was constructed to perform time resolved GISAXS and 2D-GIXD measurements, 


\section{WILEY-VCH}

respectively, simultaneously with white light reflectometry (WLR) and PL measurements. As illustrated in Figure 1-2 and Figure S1-S4, the cell provides an automated doctor blading system which is a prerequisite for the study of freshly prepared thin films. Doctor Blading was chosen as a coating method since it prototypes the roll-to-roll printing. The wellthermostated cell is equipped with a gas flow system allowing to precisely controlling the cell atmosphere (eg. solvent/inert gas mixture) and the gas temperature during the drying process. This portable and flexible powerful tool enables us to probe the kinetics and investigate the mechanisms of structure formation and manipulation processes of any organic, inorganic or hybrid thin film. It enables full characterization of solvents/additives drying, thermal and solvent vapor annealing or any method used to manipulate morphology of printed electronics. The cell atmosphere can be saturated with the solvent vapor to slow down the drying of the liquid film, enabling such studies exploiting low-flux laboratory X-ray sources.

The real time study presented here includes measurements of thin films of pristine Poly(2,5bis(3-hexadecylthiophen-2-yl)thieno[3,2-b]thiophene) named pBTTT-C16, its 1:1 blends with phenyl-c61-butyric acid methyl ester (pBTTT:PC $\left.{ }_{60} \mathrm{BM}\right)$, 4-iodophenyl-N-dodecylpyrrolidine-fullerene monoadduct (pBTTT:Pyrrolidinofullerene (AK114)) and bisPC $60 \mathrm{BM}$ (pBTTT:bisPC ${ }_{60} \mathrm{BM}$ ) and was performed at the beamline ID10 at the European Synchrotron Radiation Facility (ESRF). WLR was used to track the film thickness in real-time. The structures of pBTTT and the different fullerenes studied are shown in Figure 3. We synthesized Pyrrolidinofullerene (AK114) $\left(\mathrm{C}_{80} \mathrm{H}_{32} \mathrm{IN}, 1134.05 \mathrm{~g} \mathrm{~mol}^{-1}\right)$ by dissolving $p$ Iodobenzaldehyde (0.096 g, $0.414 \mathrm{mmol}, 1.0$ equiv) in toluene $(200 \mathrm{~mL})$ under inert conditions before $\mathrm{C}_{60}(0.300 \mathrm{~g}, 0.414 \mathrm{mmol}, 1.0$ equiv $)$ was added. The mixture was stirred for 30 minutes under exclusion of light until $\mathrm{C}_{60}$ was dissolved completely. Then $\mathrm{N}$ Dodecylglycin ( $0.121 \mathrm{~g}, 0.497 \mathrm{mmol}, 1.2$ equiv) was added and the mixture was refluxed overnight. After cooling down to room temperature and filtration the crude mixture was purified by flash chromatography $\left(\mathrm{SiO}_{2}\right.$, toluene/hexanes 2:8). The occurring brown solid was 


\section{WILEY-VCH}

dissolved in $\mathrm{CH}_{2} \mathrm{Cl}_{2}$ and precipitated with n-pentane to exclude solvent inclusions $(0.228 \mathrm{~g}$, $0.201 \mathrm{mmol}, 48 \%$ ) as illustrated in Figure 4.

Besides the in-situ measurements, 2D-GIXD measurements of completely dried thin films were also recorded for reference. For this purpose the apparently dried samples at the end of an in-situ drying experiment were removed from the sample cell and dried in vacuum to reduce the solvent content in the samples as far as possible before performing the 2D-GIXD measurement. The ex-situ measurements were conducted inside the fully evacuated beam path of the highly customized Versatile Advanced X-ray Scattering instrumenT ERlangen (VAXSTER) at the chair for Crystallography and Structural Physics (Universität ErlangenNürnberg, Germany). ${ }^{[36]}$

\section{Results and Discussion}

The 2D-GIXD detector image for the completely dried pristine pBTTT film is visualized in Figure 5 (top left). This data is fully consistent with data from literature. ${ }^{[17,23]}$ It features several diffraction peaks along $\mathrm{Q}_{\mathrm{z}}$ at $\mathrm{Q}_{\mathrm{y}}=0$ indicating an “edge-on” lamellar stacking of the conjugated polymer backbone. Pristine pBTTT-C16 forms layers of backbones that are separated by the about $21 \AA$ long alkyl side chains leading to a repeat distance $d_{100}$ of $23.33 \AA$. Blending $\mathrm{PC}_{60} \mathrm{BM}$ or Pyrrolidinofullerene (AK114) with pBTTT increases this spacing to $30.14 \AA$ and $32.17 \AA$, respectively (cf. Figure 5 top right and bottom right), indicating the formation of bimolecular crystals since fullerene molecules tend to be embedded within the polymer crystallites. On the other hand, bisP ${ }_{60} \mathrm{BM}$ (Figure 5 bottom left) does not seem to be intercalated as the 100 repeat distance is preserved. This is probably due to the extra side group that makes bisPC ${ }_{60} \mathrm{BM}$ too large to fit between the polymer side chains. ${ }^{[37]}$ Furthermore, the additional side group increases the relative polarity of the fullerene and further decreases favorable interactions between the fullerene and the polymer phase. ${ }^{[16,19]}$ The interferences in the 2D-GIXD image of the pristine pBTTT film at $\mathrm{Q}_{\mathrm{y}}=1.41 \AA^{-1}$ and $\mathrm{Q}_{\mathrm{y}}=1.67 \AA^{-1}$ (at low $\mathrm{Q}_{\mathrm{z}}$ ), respectively, correspond to the intramolecular stacking (003) and the $\pi$-stacking $\mathrm{d}_{010}$ of $3.76 \AA$, 


\section{WILEY-VCH}

where (001) would correspond to the repeat unit length of the polymer of $13.38 \AA$. These interferences are in agreement with the previously reported orthorhombic lattice of the pure

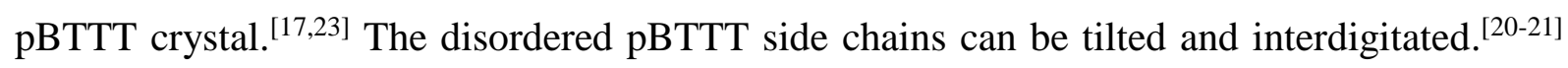
This leads together with backbone $S \cdots S$ and $\pi \cdots \pi$ interactions to the formation of straight channels along the $\pi$-stacking direction that perfectly host fullerene molecules in the intercalated blends. ${ }^{[21,38]}$ The shift of $(010)$ to $0.76 \AA^{-1}$ indicates that the $\pi$-stacking distance $\mathrm{d}_{010}$ has increased to $8.3 \AA$ which is close to the reported minimum $\mathrm{C}_{60}$ center-to-center distance in $\mathrm{PC}_{60} \mathrm{BM}$ crystals. ${ }^{[38-39]}$ The in-plane peak at $\mathrm{Q}_{\mathrm{y}}=0.48 \AA^{-1}$ can be attributed to fullerene's repeat distance along the intramolecular stacking direction $\mathrm{d}_{001}$ of $13.09 \AA$. These findings are consistent with the monoclinic bimolecular lattice suggested elsewhere. ${ }^{[17,23]}$ According to [39], we assume the formation of a $\mathrm{PC}_{60} \mathrm{BM}$ sub-lattice hosted in the 1-D channels which contain two fullerene molecules along the lamellar stacking direction. A similar co-crystal is obtained by blending pBTTT-C16 with Pyrrolidinofullerene (AK114), but its long side groups need to be oriented along lamellar stacking direction.

We monitored the formation and development of these self-assembled structures upon drying. A video sequence of consecutive detector images of a corresponding in-situ 2D-GIXD measurement is available in the electronic supplementary information. At the beginning of the drying process, the detector images are dominated by two broad solvent peaks which decay slowly with increasing drying time before they vanish abruptly within some seconds only. At the same time of the disappearance of solvent peaks, the crystalline structure of the solidified polymer becomes visible and the corresponding Bragg interferences do shift to larger Qvalues upon further drying (cf. Figure 6).

The observed drying process can be divided into three distinct temporal periods. The primary drying period starts with the formation of the thin liquid film which abruptly increases the liquid/air interface drastically. During this first drying period which lasts for about $20 \mathrm{~s}$ to $40 \mathrm{~s}$, the solvent fraction linearly decreases as it is found by the decay of the two broad 


\section{WILEY-VCH}

interferences due to the local order of the solvent molecules in real time GIXD measurements (cf. Figure 6 and Figure 7). According to these measurements the thickness of the film calculated from the interference fringes of the optical reflectance spectra recorded in parallel to the GISAXS measurements during the drying process exhibits the same trend as it can be extracted from Figure 8 and Figure S6.

The secondary drying period which lasts for another $20 \mathrm{~s}$ to $40 \mathrm{~s}$ period starts with the onset of the nucleation of the polymer crystalline phase which is indicated in Figure 9 and Figure 10. The enhanced slope of the drying curves compared to those of the first drying period (Figure 7) exhibit that the evaporation rate in the second drying period is higher than it was in the first drying period. In the same time as the solvent peaks vanish, crystalline peaks of the polymer become continuously more intense. In Figure 9 the lamellar spacings $d_{100}$ of the polymer crystals is plotted as a function of drying time. The first points in the plots occur at times the 100 reflection could be observed for the first time. This time indicates the end of the first and the beginning of the second drying period.

Immediately after the onset of crystal formation, the initially quite large inter-lamellar distances $d_{100}$ start to shrink due to the reduction of solvent concentration within the crystallites. It is obvious from the curves in Figure 9 that the decrease of the $d_{100}$-value is limited for the samples for which $\mathrm{PC}_{60} \mathrm{BM}$ and Pyrrolidinofullerene (AK114) was used as fullerene phase. In this context, we have to respect that fullerenes might be intercalated between the polymer side chains when there is enough free volume to accommodate the fullerene molecule. ${ }^{[38]}$ Fullerenes like $\mathrm{PC}_{60} \mathrm{BM}$ and Pyrrolidinofullerene (AK114) are small enough to be intercalated whereas bisPC ${ }_{60} \mathrm{BM}$ is clearly larger than the polymer intermolecular distance and can therefore not be intercalated. Consequently, no or only a small reduction of the $\mathrm{d}_{100}$-spacings is observed upon drying for $\mathrm{PC}_{60} \mathrm{BM}$ and Pyrrolidinofullerene (AK114) containing samples as the fullerenes intercalate into the polymer crystalline domains. This strongly suggests that the intercalation process obviously takes place before or with the 


\section{WILEY-VCH}

formation of the crystalline polymer domains as only a very limited shrinking of the $\mathrm{d}_{100^{-}}$ spacings is observed after their formation. Obviously, the solvent placed between the polymer chains in the pristine polymer film and the bisPC ${ }_{60} \mathrm{BM}$ containing film is replaced here by the intercalated fullerenes. The fullerene intercalation hinders the reduction of the $\mathrm{d}_{100}$-spacings of the crystalline domains upon drying. Furthermore, it is remarkable that the $\mathrm{d}_{100}$-spacing is also not reduced after excessive drying in vacuum for the intercalation compounds. This is in clear contrast to the intercalation-free films for which a strong further reduction of the $\mathrm{d}_{100^{-}}$ spacings is observed upon drying in vacuum (cf. Figure 9).

In a third drying period no significant increase of the polymer crystallinity is observed (cf. Figure S7) although the positions of the 100-Bragg reflections are still slightly changing especially for the pristine polymer film (cf. Figure 9 and Figure 10). The film in this period is thin and solid resulting in the appearance of a "Yoneda" peak which is due to the scattering enhancement at the critical angle of the film/air interface in the time resolved GISAXS measurements (cf. Figure 10). The drying speed of the films with non-intercalated blends is significantly slower in the third period than that of the films with fullerene intercalated polymers (cf. Figure 9). We assume that the solvent placed in the open intercalation sites of the polymers is less mobile and accordingly the drying speed of these films is remarkably reduced. The sub-lattice of the intercalated fullerenes seems not to be changed after the formation of the bimolecular crystals (Figure S5).

The azimuthal width (FWHM) of the polymer 100 Bragg reflections constitutes a measure of the preferred orientation (mosaicity) of the crystalline polymer domains. As it can be extracted from the plots in Figure 5 and Figure S8, mosaicities of about $19.5^{\circ}$ (FWHM) for the intercalated and $8.6^{\circ}$ for the non-intercalated completely dried blends are observed. The biomolecular intercalation crystallites are obviously less good oriented with respect to the substrate as the neat polymer edge-on crystallites. The mosaicity can be also correlated with the spatial location of crystal nucleation. Low mosaicity is attributed to heterogeneous 


\section{WILEY-VCH}

nucleation at the substrate/liquid planar interfaces while higher mosaicity is attributed to homogenous bulk nucleation. ${ }^{[40]}$ The broader mosaicity of the crystalline polymer domains in the intercalated compared to the non-intercalated blends therefore suggests a distribution of nucleation sites which is more homogeneous. The Yoneda peak for the intercalation samples is found to be split up into two closely neighbored peaks (cf. Figure S9) which might indicate a binary phase separation structure of the film leading to two distinctly different critical angles. Here a lateral phase separation on the micrometer scale is assumed which would lead to largely independent reflections of the different phases. The angle of one of the observed peaks is really close to that of pristine pBTTT-C16 at $0.12^{\circ}$. The other interference maximum might then be attributed to the Yoneda peak of the bimolecular crystals.

\section{Conclusion}

Structure formation within thin liquid films produced by doctor blading has been studied by time resolved in-situ GIXD and GISAXS measurements. For this purpose a special in-house built sample cell has been used. It was aimed to observe the characteristics of the structure formation of intercalating polymer-fullerene-blends. We observed three distinct stages of drying: Primary drying of the liquid layer whose thickness diminishes from about $10 \mu \mathrm{m}$ at the beginning to about $1 \mu \mathrm{m}$ at the end of this period. The thickness of the formed film continues to decrease during the next dying period to about $100 \mathrm{~nm}$. During this secondary drying period the polymer and bimolecular intercalation crystals start to nucleate and grow, respectively. This period is characterized by the highest solvent evaporation rate. The development of uni-dimensional fullerene channels along the $\pi$-stacking direction of the polymer crystallites was confirmed. Intercalation was observed for $\mathrm{PC}_{60} \mathrm{BM}$ and Pyrrolidinofullerene (AK114) into the pBTTT-C16 polymer crystalline domains. BisPC ${ }_{60} \mathrm{BM}$ was found not to intercalate due to its larger size. The intercalation takes place before or during crystallization of the polymer. In contrast to the non-intercalated polymer, the intercalated polymer keeps its volume upon further drying, even when finalizing the drying at 


\section{WILEY-VCH}

ambient conditions in vacuum. Intercalation speeds up the drying process resulting in stable morphologies in less than one minute. Lateral variations of film composition give rise to phase separation on the micron scale in the intercalated blends. The non-intercalated polymer crystallites exhibit significantly greater preference for edge-on orientation. Our observations provide insight into the structure development of intercalating and non-intercalating printed BHJ polymer:fullerene blends. They potentially assist the future optimization and understanding of structure formation in this category of materials.

\section{Experimental Section}

\section{Materials:}

pBTTT was synthesized with C16 side chains by Prof. M. Heeney and Prof. I. McCulloch, Imperial College, London. The pBTTT-C16 had a number average molecular mass of $\mathrm{Mn}=$ $35 \mathrm{KDa}$ with a polydispersity of $2 . \mathrm{PC}_{60} \mathrm{BM}(99.5 \%)$ and bis $\mathrm{PC}_{60} \mathrm{BM}$ were purchased from Solenne BV. 1,2-dichlorobenzene (99\%) was purchased from Sigma-Aldrich. All films were doctor bladed from their ortho-dichlorobenzene (oDCB) solution at $60{ }^{\circ} \mathrm{C}$ with total concentrations of $15 \mathrm{mg} \mathrm{ml}^{-1}$ in oDCB onto silicon substrates purchased from Silicon Materials with natural $\mathrm{SiO}_{2}$. The wafers were cut in rectangular pieces $(20 \mathrm{~mm}$ x $80 \mathrm{~mm})$, cleaned mechanically with soapy de-ionized water, rinsed with de-ionized water, and ultrasonicated with acetone and then with iso-propanol. The substrates were dried with nitrogen and kept in a desiccator to avoid any humidity effects on the surface.

\section{GIXD/GISAXS:}

Samples were measured right after doctor blading pBTTT:fullerene 1:1 wt $\%$ blends from a oDCB solution with total concentrations of $15 \mathrm{mg} \mathrm{ml}^{-1}$ onto silicon substrates $(2 \mathrm{~cm} \mathrm{x} 8 \mathrm{~cm})$ at $60{ }^{\circ} \mathrm{C}$ and dry $\mathrm{He}$ atmosphere. 2D GIXD measurements were performed at ESRF on beamline ID10 using a Dectris 300K hybrid-pixel area detector located at a distance of $170.13 \mathrm{~mm}$ from the sample center. The 2D GIXD/GISAXS measurements were carried out at energy of 10 $\mathrm{keV}$ and an incidence angle of $0.16^{\circ}$ which is smaller than the critical angle of total reflection 


\section{WILEY-VCH}

of the substrate to limit the penetration depth and the scattering to the thin layer. Grazing incidence geometry of the incident X-ray with respect to the sample surface is used here to enhance the scattered intensity, to maximize the scattering volume, and to access the 3D structure of the studied thin films (lateral and normal direction). The film thickness was obtained by simultaneously recording the normal incidence spectral reflectometry. Approximately $120 \mu \mathrm{L}$ of the solution were dispensed from automated syringe under the edge of a blade fixed at $400 \mu \mathrm{m}$ above the substrate surface. The substrate and He atmosphere temperature was $60{ }^{\circ} \mathrm{C}$. The blade was immediately translated after injection at $15 \mathrm{~mm} \mathrm{~s}^{-1}$ of velocity. The final BHJ films thicknesses were nominally 20, 90, 50, $100 \mathrm{~nm}$ for pBTTT, pBTTT:bisPC ${ }_{60} \mathrm{BM}, \mathrm{pBTTT}: \mathrm{PC}_{60} \mathrm{BM}$ and pBTTT:Pyrrolidinofullerene (AK114), respectively. The beamline slits were adjusted to produce a nominally $100 \mu \mathrm{m}$ high beam which illuminates the $2 \mathrm{~cm}$ wide substrate. The footprint in the sample position should be roughly $2 \mathrm{~cm} \times 100$ $\mu \mathrm{m}$. The beam size at the detector position is less than one pixel $(172 \mu \mathrm{m} \times 172 \mu \mathrm{m})$. In situ GISAXS was performed at the same beamline with the 2D image detector-to-sample distance $1530.37 \mathrm{~mm}$ and an incidence angle of $0.25^{\circ}$ to obtain a clear separation between the critical angles of the involved materials and the specular peak. The detector was calibrated with a silver behenate standard. GIXD data was reduced with the Nika software package[41] while GISAXS data was reduced using dpdak software.[42] The whole cell was moved $55.5 \mu \mathrm{m}$ horizontally during the measurement after each 0.75 seconds of exposure to avoid radiation damage. The difference in drying time between two consecutive frames is $3.7 \mathrm{~ms}$ results in $0.67 \mathrm{~s}$ drying time misfit between the start and end positions. This is less than our time resolution. The total sample area measured was $1 \times 2 \mathrm{~cm}^{2}$. At the beginning of the coating process, the applicator blocks the incident X-ray beam. The applicator moves at a speed of 15 $\mathrm{mm} \mathrm{s}^{-1}$. Respecting that the distance between the blade and the beam blocking frame of the applicator is $15 \mathrm{~mm}$, the first time frame of the recorded X-ray data with full scattering intensity corresponds to a time of $15 \mathrm{~mm} / 15 \mathrm{~mm} \mathrm{~s}^{-1}=1 \mathrm{~s}$ after film formation. The ex-situ 


\section{WILEY-VCH}

measurements were recorded with VAXSTER instrument using its former $30 \mathrm{~W} \mathrm{Cu} \mathrm{K} \alpha(\lambda$ $=1.5418 \AA$ ) Microfocus X-ray source GeniX with a FOX 2D parallel beam mirror optics (Xenocs, Sassenage, France). ${ }^{[36]}$ The beam was shaped by two automated double slit systems (aperture sizes $0.7 \times 0.7 \mathrm{~mm}^{2}$ and $0.4 \times 0.4 \mathrm{~mm}^{2}$ ) with a distance of about $1.2 \mathrm{~m}$. The second slit system consists of four "scatterless" silicon single crystal blades. All ex-situ measurements were performed at $22{ }^{\circ} \mathrm{C}$ inside the fully evacuated beam path in front of the 2D Pilatus3 $300 \mathrm{~K}$ detector (Dectris Ltd., Baden, Switzerland). The collimation line was tilted and shifted with respect to the horizontal plane allowing grazing incidence angles which maximize the scattering volume and enhance the scattered intensity. The incidence angle $\alpha$ of about $0.18^{\circ}$ was chosen. The sample-detector distance (sdd) was calibrated to $176.338 \mathrm{~mm}$ using a silver behenate standard, providing a beam size of about $0.5 \times 20 \mathrm{~mm}^{2}$ at the sample position.

\section{Supporting Information}

Video sequences of consecutive detector images for the real time GIXD measurements of the formation of pristine pBTTT and pBTTT:Pyrrolidinofullerene (AK114) thin films are available via the Wiley Online Library at http:// or from the author.

\section{Acknowledgements}

The authors would like to acknowledge the funding of the Deutsche Forschungsgemeinschaft (DFG) through the Cluster of Excellence Engineering of Advanced Materials. We thank "European Synchrotron Radiation Facility" ESRF for financing our beam time and appreciate the support of Karim Lhoste and Oleg Konovalov at the beamline ID10. We thank SFB 953 project "synthetic carbon allotropes" for providing the Pyrrolidinofullerene. We gratefully acknowledge Christian Bär, Herbert Lang, and Jürgen Grasser for constructing the in-situ GIXD/GISAXS cell. Thaer Kassar and Nusret S. Güldal contributed equally to this work.

Notes: The authors declare no competing financial interest. 


\section{WILEY-VCH}

Received: ((will be filled in by the editorial staff))

Revised: ((will be filled in by the editorial staff)) Published online: ((will be filled in by the editorial staff))

[1] P. W. M. Blom, V. D. Mihailetchi, L. J. A. Koster, D. E. Markov, Adv. Mater. 2007, 19, 1551.

[2] A. C. Mayer, S. R. Scully, B. E. Hardin, M. W. Rowell, M. D. Mcgehee, Materials Today 2007, 10, 28.

[3] B. C. Thompson, J. M. J. Fréchet, Angew. Chem. Int. Ed. 2008, 47, 58.

[4] S. H. Park, A. Roy, S. Beaupré, S. Cho, N. Coates, J. S. Moon, D. Moses, M. Leclerc, K. Lee, A. J. Heeger, Nat Photonics 2009, 3, 297.

[5] Solarmer Energy Inc., Press Release 2009, July 7.

[6] Y. Liang, Z. Xu, J. Xia, S.-T. Tsai, Y. Wu, G. Li, C. Ray, L. Yu, Adv. Mater. 2010, 22, 135.

[7] NREL's Best Research Cell Efficiencies as of May 2015.

[8] C. J. Brabec, S. Gowrisanker, J. J. M. Halls, D. Laird, S. Jia, S. P. Williams, Adv. Mater. 2010, 22, 3839.

[9] T. M. Clarke, J. R. Durrant, Chem. Rev. 2010, 110, 6736.

[10] L. S. C. Pingree, O. G. Reid, D. S. Ginger, Adv. Mater. 2009, 21, 19.

[11] D. S. Germack, C. K. Chan, R. J. Kline, D. A. Fischer, D. J. Gundlach, M. F. Toney, L. J. Richter, D. M. Delongchamp, Macromolecules 2010, 43, 3828.

[12] N. D. Treat, M. A. Brady, G. Smith, M. F. Toney, E. J. Kramer, C. J. Hawker, M. L. Chabinyc, Adv. Energy Mater. 2010, 1, 82.

[13] D. Chen, F. Liu, C. Wang, A. Nakahara, T. P. Russell, Nano Lett. 2011, 11, 2071. 


\section{WILEY-VCH}

[14] B. A. Collins, E. Gann, L. Guignard, X. He, C. R. Mcneill, H. Ade, J. Phys. Chem. Lett. 2010, 1,3160 .

[15] W. Yin, M. Dadmun, ACS Nano 2011, 5, 4756.

[16] N. C. Cates, R. Gysel, Z. Beiley, C. E. Miller, M. F. Toney, M. Heeney, I. Mcculloch, M. D. Mcgehee, Nano Lett. 2009, 9, 4153.

[17] A. C. Mayer, M. F. Toney, S. R. Scully, J. Rivnay, C. J. Brabec, M. Scharber, M. Koppe, M. Heeney, I. Mcculloch, M. D. Mcgehee, Adv. Funct. Mater. 2009, 19, 1173.

[18] C.-K. Lee, C.-W. Pao, J. Phys. Chem. C 2012, 116, 12455.

[19] C. Bruner, N. C. Miller, M. D. Mcgehee, R. H. Dauskardt, Adv. Funct. Mater. 2013, 23, 2863.

[20] N. C. Miller, R. Gysel, C. E. Miller, E. Verploegen, Z. Beiley, M. Heeney, I. Mcculloch, Z. Bao, M. F. Toney, M. D. Mcgehee, J. Polym. Sci. B Polym. Phys. 2011, 49, 499.

[21] N. C. Miller, E. Cho, M. J. N. Junk, R. Gysel, C. Risko, D. Kim, S. Sweetnam, C. E. Miller, L. J. Richter, R. J. Kline, M. Heeney, I. McCulloch, A. Amassian, D. Acevedo-Feliz, C. Knox, M. R. Hansen, D. Dudenko, B. F. Chmelka, M. F. Toney, J.-L. Brédas, M. D. McGehee, Adv. Mater. 2012, 24, 6071.

[22] X. He, B. A. Collins, B. Watts, H. Ade, C. R. McNeill, Small 2012, 8, 1920.

[23] M. L. Chabinyc, M. L., M. F. Toney, R. J. Kline, I. McCulloch, M. J. Heeney, Am. Chem. Soc. 2007, 129, 3226.

[24] B.H. Hamadani, D.J. Gundlach, I. McCulloch and M. Heeney, Appl. Phy. Lett. 2007, 91, 243512.

[25] J.E. Parmer, A.C. Mayer, B.E. Hardin, S.R. Scully, M.D. McGehee, M. Heeney, Appl. Phys. Lett. 2008, 92, 113309.

[26] Q. Sun, K. Park, L. Dai, J. Phys. Chem. C 2009, 113, 7892.

[27] A. J. Heeger, Adv. Mater. 2014, 26, 10. 


\section{WILEY-VCH}

[28] Maturová K., S. S. V. Bavel, M. M. Wienk, R. A. J. Janssen, M. Kemerink, Nano Lett. 2009, 9, 3032 .

[29] I.-W. Hwang, D. Moses, A. J. Heeger, J. Phys. Chem. C 2008, 112, 4350.

[30] N. Banerji, J. Mater. Chem. C 2013, 1, 3052.

[31] A. Pivrikas, N. S. Sariciftci, G. Juška, R. Österbacka, Prog. Photovolt: Res. Appl. 2007, $15,677$.

[32] I.-W. Hwang, J. Y. Kim, S. Cho, J. Yuen, N. Coates, K. Lee, M. Heeney, I. Mcculloch, D. Moses, A. J. Heeger, J. Phys. Chem. C 2008, 112, 7853.

[33] L. J. A. Koster, V. D. Mihailetchi, P. W. M. Blom, Appl. Phys. Lett. 2006, 88, 052104.

[34] J. Liu, L. Chen, B. Gao, X. Cao, Y. Han, Z. Xie, L. Wang, J. Mater. Chem. A 2013, 1, 6216.

[35] J. Liu, Q. Liang, H. Wang, M. Li, Y. Han, Z. Xie, L. Wang, J. Phys. Chem. C 2014, 118, 4585.

[36] M. Schmiele, S. Gehrer, M. Westermann, F. Steiniger, T. Unruh, J. Chem. Phys. 2014, $140,214905$.

[37] M. Lenes, G.-J. A. H. Wetzelaer, F. B. Kooistra, S. C. Veenstra, J. C. Hummelen, P. W. M. Blom, Adv. Mater. 2008, 20, 2116.

[38] L. Zhang, F. Liu, Y. Diao, H. S. Marsh, N. S. Colella, A. Jayaraman, T. P. Russell, S. C. B. Mannsfeld, A. L. Briseno, J. Am. Chem. Soc. 2014, 136, 18120.

[39] R. Colle, G. Grosso, A. Ronzani, M. Gazzano, V. Palermo, Carbon 2012, 50, 1332.

[40] R. J. Kline, M. D. Mcgehee, M. F. Toney, Nat Mater 2006, 5, 222.

[41] J. Ilavsky, J Appl Crystallogr 2012, 45, 324.

[42] G. Benecke, W. Wagermaier, C. Li, M. Schwartzkopf, G. Flucke, R. Hoerth, I. Zizak, M. Burghammer, E. Metwalli, P. Müller-Buschbaum, M. Trebbin, S. Förster, O. Paris, S. V. Roth, P. Fratzl, J Appl Crystallogr 2014, 47, 1797. 


\section{WILEY-VCH}

[43] T. Xiao, H. Xu, G. Grancini, J. Mai, A. Petrozza, U. S. Jeng, Y. Wang, X. Xin, Y. Lu, N.

S. Choon, H. Xiao, B. S. Ong, X. Lu, N. Zhao, Sci. Rep. 2014, 4, 5211.

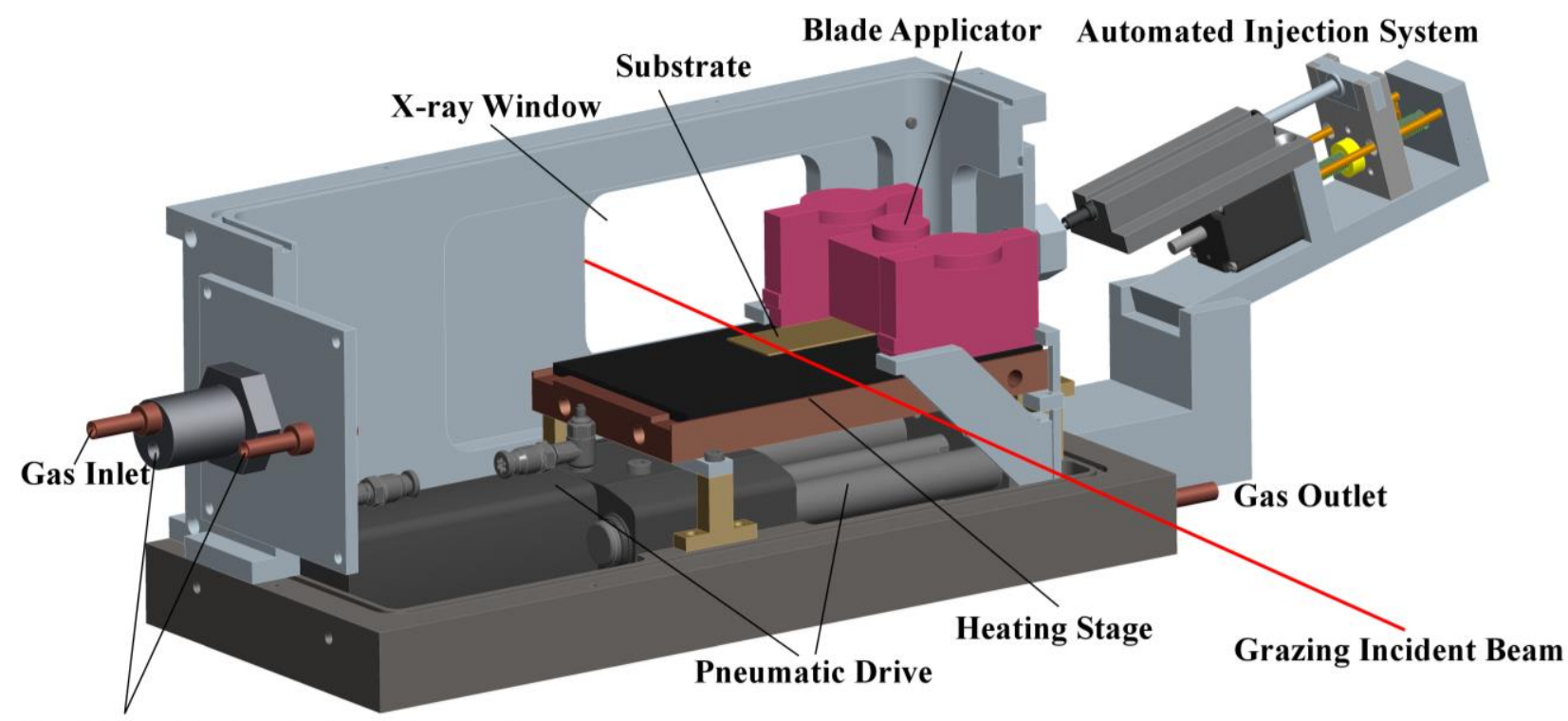

Hot Water Recirculation Inlet/Outlet

Figure 1. Three dimensional technical drawing of the sample cell providing automated doctor blading. The front door including the first X-ray window, gas and water hoses as well as the optical devices on the top lid are not shown for clarity.

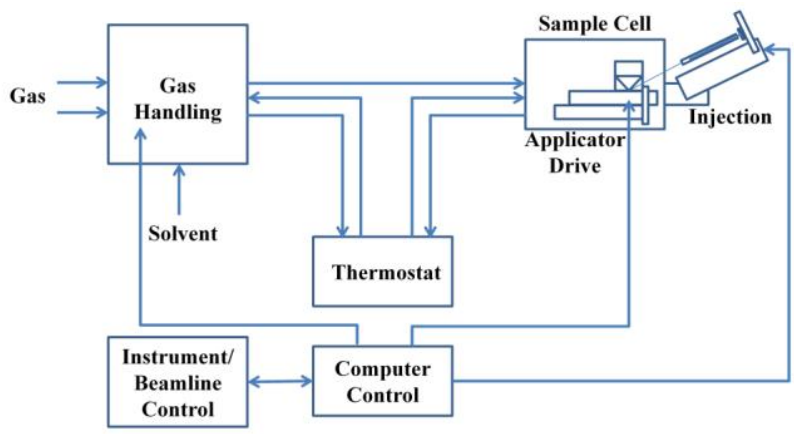

Figure 2. Schematic illustration of the experimental setup for real time studies of structure formation and manipulation of thin films. 


\section{WILEY-VCH}

(a)

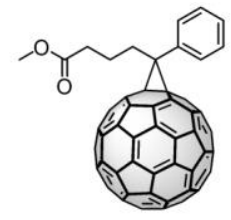

(c)

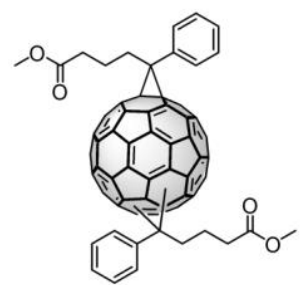

(b)

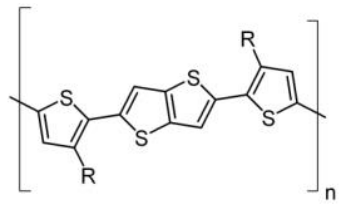

(d)

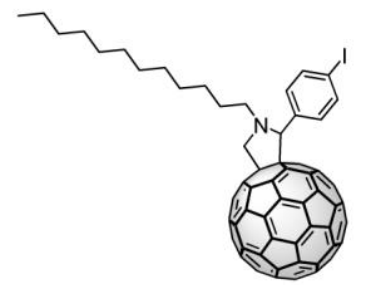

Figure 3. The chemical structure of the materials used in this work: (a) $\mathrm{PC}_{60} \mathrm{BM}$, (b) The pBTTT-C16 variant of pBTTT $\left(\mathrm{R}=\mathrm{C}_{16} \mathrm{H}_{32}\right),(\mathrm{c})$ bisPC ${ }_{60} \mathrm{BM}$ and (d) Pyrrolidinofullerene (AK114).

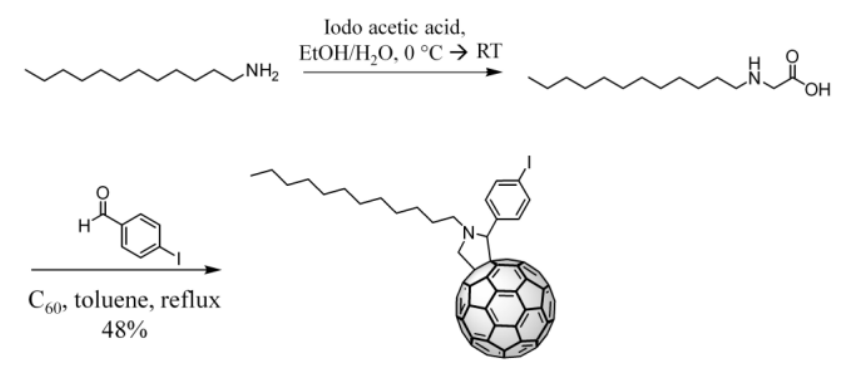

Figure 4. Illustration of the synthesis of Pyrrolidinofullerene (AK114). 


\section{WILEY-VCH}
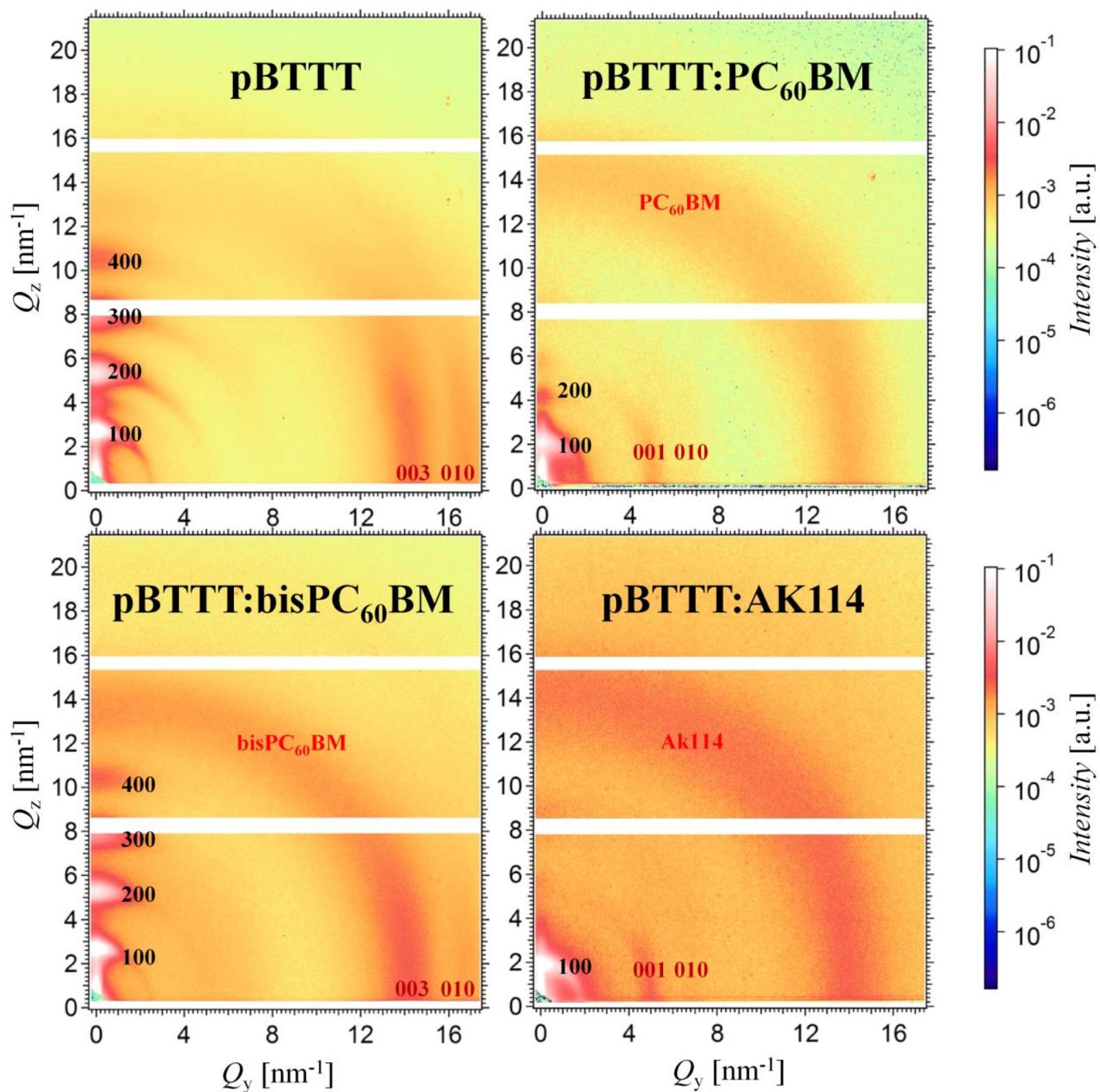

Figure 5. Ex-situ GIXD detector images of the completely dried samples measured with the VAXSTER instrument. 


\section{WILEY-VCH}

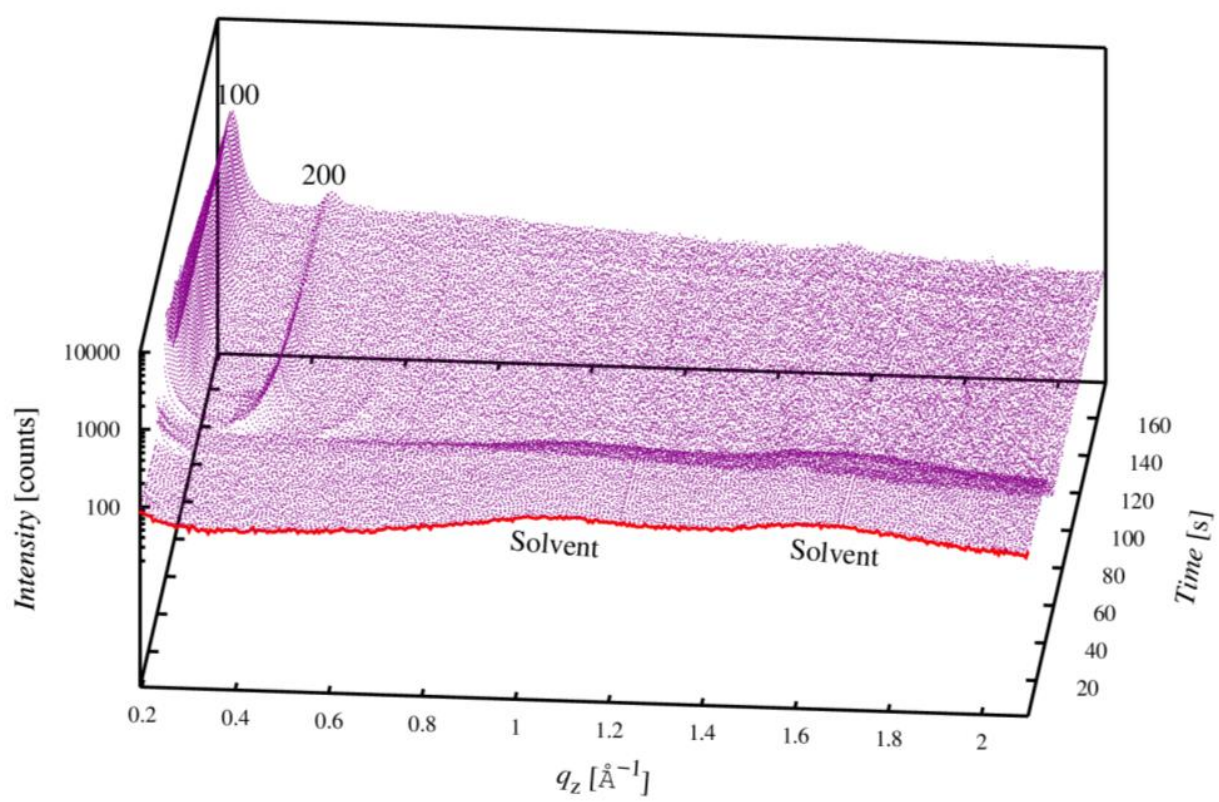

Figure 6. Vertical cuts at $\mathrm{Q}_{\mathrm{y}}=0$ of the detector images of the time resolved GIXD measurements of pristine pBTTT-C16 as a function of the drying time.

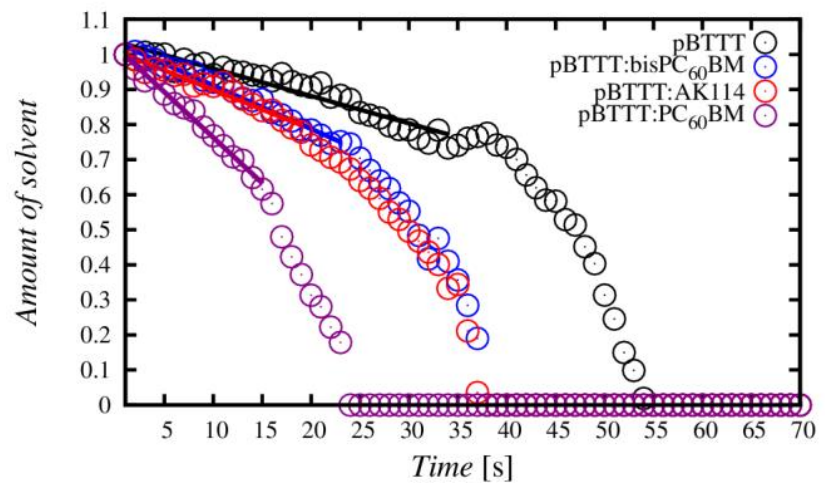

Figure 7. Relative change in solvent quantity during drying as derived from the intensity of the two solvent peaks in real time GIXD measurements. The linear decrease of the amount of solvent within the film marks the primary drying period.

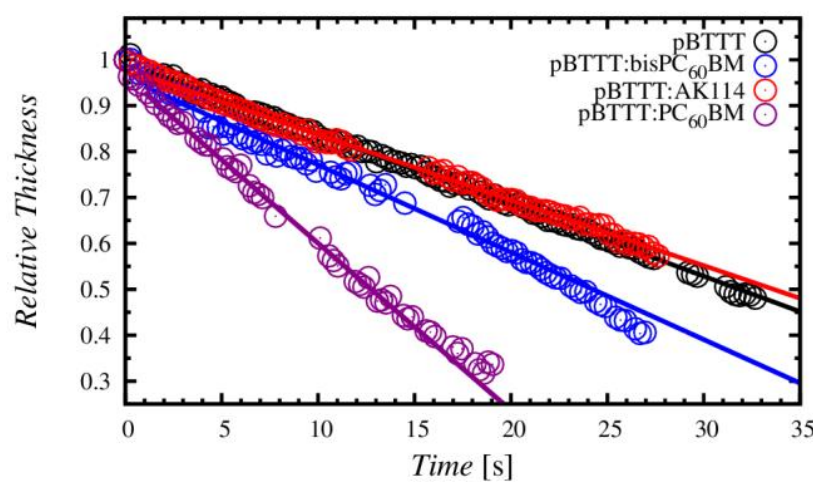

Figure 8. Relative change in film thickness evolution monitored by WLR. 


\section{WILEY-VCH}

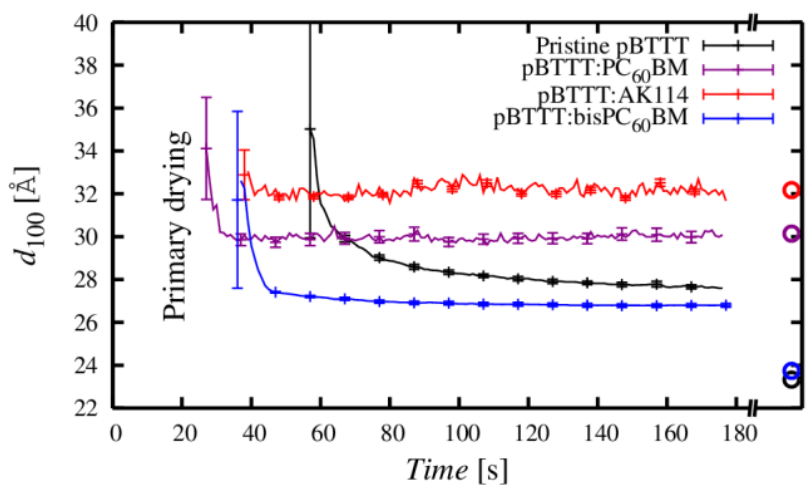

Figure 9. Temporal change of the lamellar spacing of pBTTT crystallites of different blends during drying as derived from the time resolved GIXD measurements. The open circles on the right hand side represent the corresponding $d_{100}$ values of the films after extensive drying in vacuum.

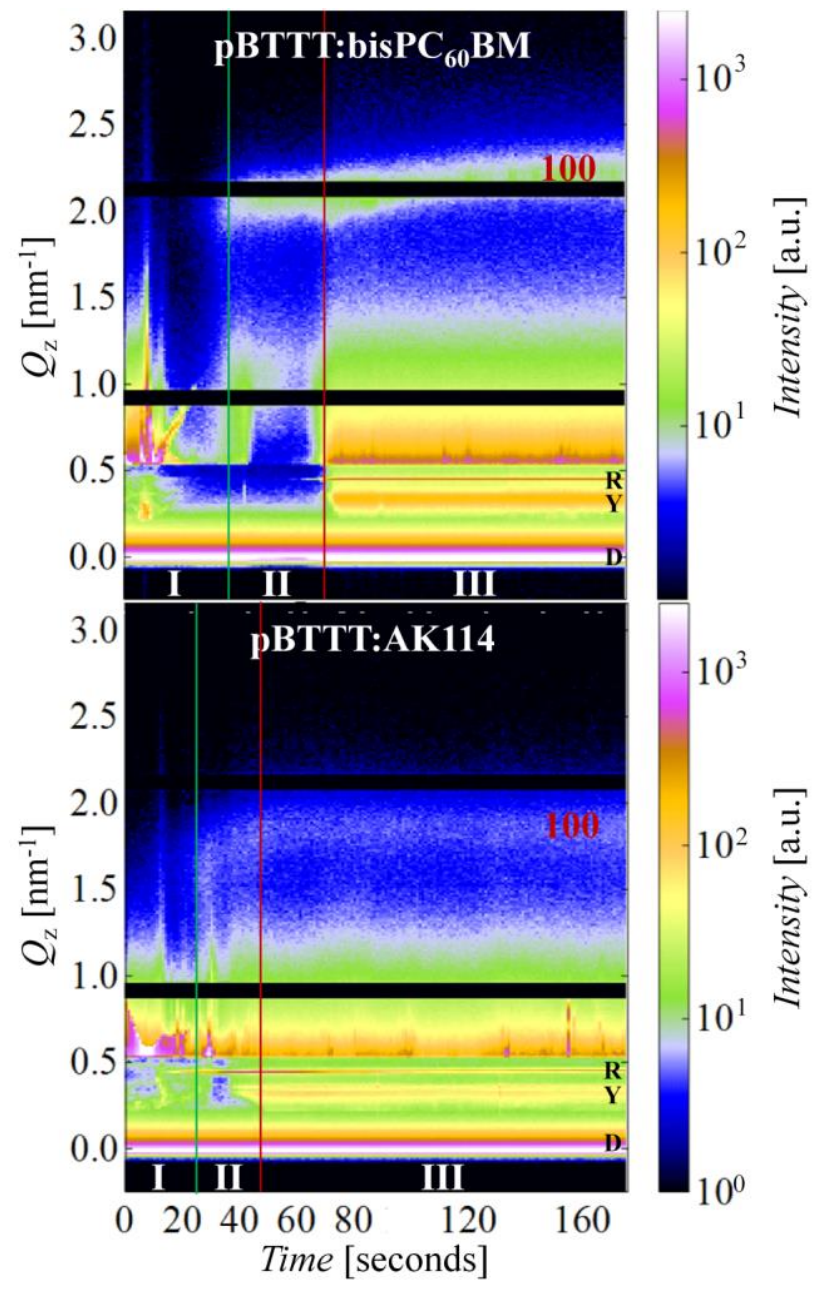

Figure 10. Vertical cuts at $\mathrm{Q}_{\mathrm{y}}=0$ of the detector images of the time resolved GISAXS measurements as a function of the drying time. The green and red lines separate the three 


\section{WILEY-VCH}

different drying periods indicated at the bottom of each image. Crystallization of pBTTT as evidenced by the appearance of 100 peak, marks the beginning of the second drying stage. The appearance of the Yoneda peak indicates the beginning of the third stage. S and $\mathrm{Y}$ indicate the specular and Yoneda peaks while D refers to the direct beam. 


\section{WILEY-VCH}

Real time GIXD and GISAXS measurements during formation of a thin active layer upon drying of a doctor-bladed thin liquid film are presented. The aim is to find the formation route of the final structure of bimolecular crystalline phases. The special fully automated sample cell used for this purpose is described in details. In contrast to the non-intercalated polymer, the intercalated polymer keeps its volume upon further drying, even when finalizing the drying at ambient conditions in vacuum. Intercalation speeds up the drying process resulting in stable morphologies in less than one minute.

\section{Kinetics of fullerenes intercalation}

Thaer Kassar, Nusret S. Güldal, Marvin Berlinghof, Tayebeh Ameri, Andreas Kratzer, Bob C. Schroeder, Giovanni Li Destri, Andreas Hirsch, Martin Heeney, Iain McCulloch, Christoph J. Brabec, and Tobias Unruh*

Real Time Investigation of Intercalation and Structure Evolution in Printed Polymer:Fullerene Bulk Hetero-Junction Thin Films

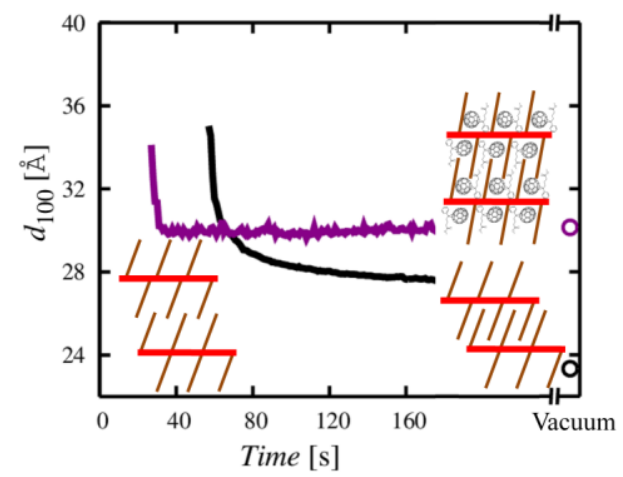




\section{WILEY-VCH}

Copyright WILEY-VCH Verlag GmbH \& Co. KGaA, 69469 Weinheim, Germany, 2013.

\section{Supporting Information}

\section{Real Time Investigation of Intercalation and Structure Evolution in Printed Polymer:Fullerene Bulk Hetero-Junction Thin Films}

Thaer Kassar, Nusret S. Güldal, Marvin Berlinghof, Tayebeh Ameri, Andreas Kratzer, Bob C. Schroeder, Giovanni Li Destri, Andreas Hirsch, Martin Heeney, Iain McCulloch, Christoph J. Brabec, and Tobias Unruh*

Fully automated in-house built sample cell for time resolved in-situ GIXD, GISAXS, photo-luminescence (PL) and white-light/laser spectroscopic ellipsometry measurements:

We constructed a novel sample cell with the aim of analyzing the structure formation processes taking place during the formation of a thin active layer upon drying of a doctorbladed thin liquid film. It features tight aluminum housing with two double Nalophan X-ray transparent windows purchased from Kalle $\mathrm{GmbH}$ and an integrated automated solution injection system which allows a reproducible and accurate dosing of the coating liquid. It was built utilizing a stepper motor with precision lead screw, nut and two limit switches. The motor is used to push a piston in syringe tube to eject liquids via hollow long needle on the substrate inside the cell. Automated doctor-blade is integrated through an applicator with gap height adjustable from $5 \mu \mathrm{m}-3 \mathrm{~mm}$ purchased from Zehntner GmbH. The applicator moves smoothly on the top of a perfectly flat Ceran glass-ceramic plate mounted on the top of a cupper heating stage which is equipped with running water channels. The drying speed can be regulated by controlling the solvent vapor pressure and the temperature inside the cell. For a single measurement, temperature and gas pressure of the cell are fully equilibrated first and subsequently a droplet of the formulation is incubated via the automated injection system to 


\section{WILEY-VCH}

the substrate under the applicator blade which starts moving to spread the liquid over the substrate.

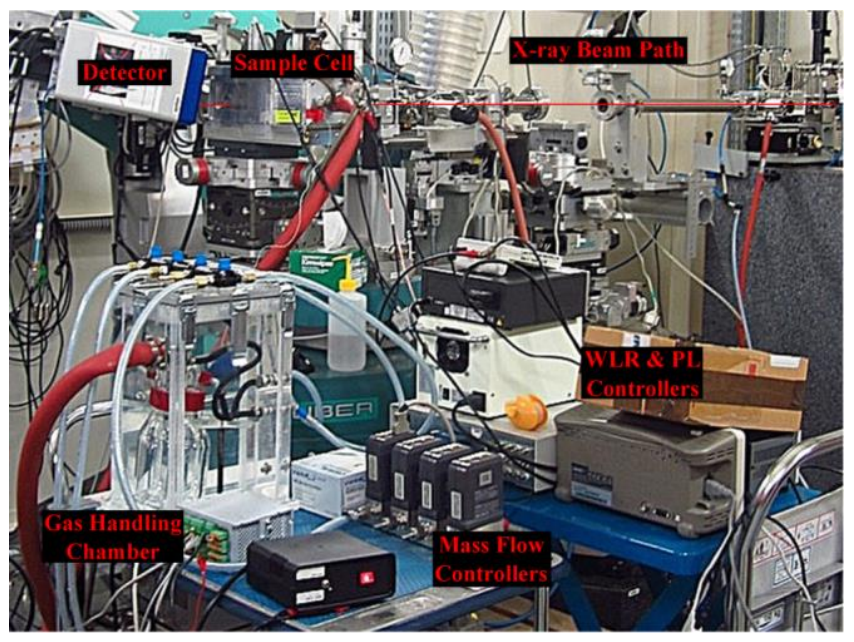

Figure S1. The experimental setup installed at ESRF ID10 beamline. The washing bottles filled with solvent for saturating the inert gas flow with solvent vapor and the mass flow controllers of the gas flow system are visible on the small table in the foreground.

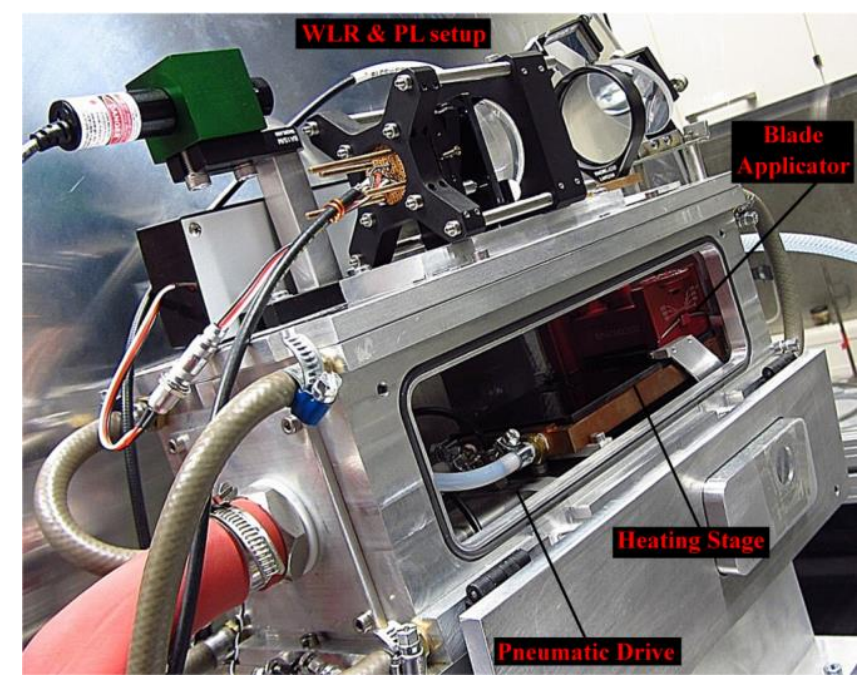

Figure S2. The applicator inside the sample cell is ready for coating as seen by opening its first window. The setup for WLR and PL measurements is installed on top of the sample cell (cf. Text and supplementary information). The coating liquid is injected by an automated syringe directly before the coating process. 


\section{WILEY-VCH}

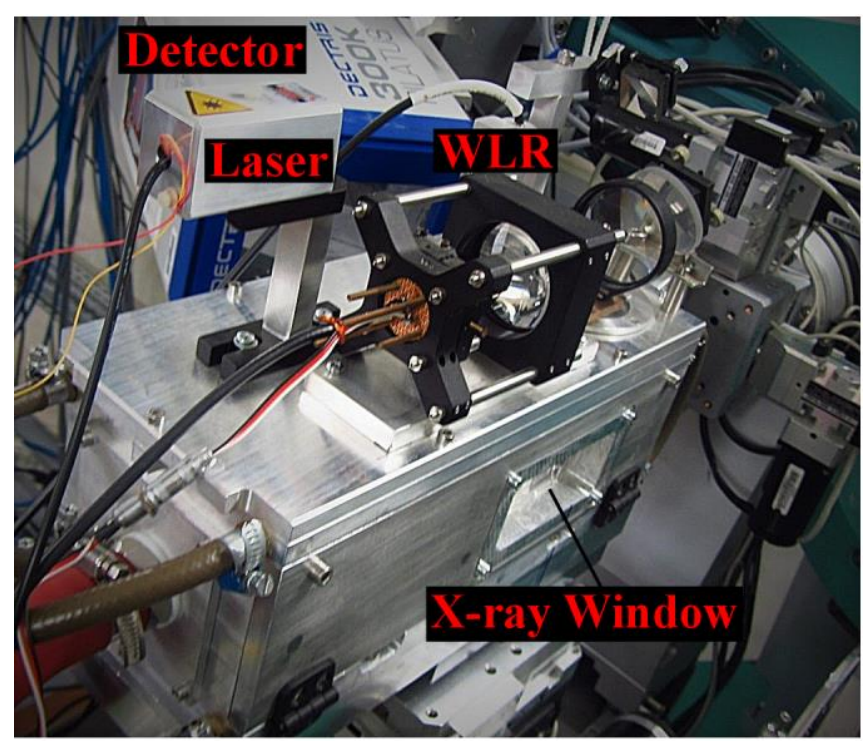

Figure S3. The sample cell is implemented on the sample stage at ESRF ID10 beamline. The optical parts are mounted on top.

The blade is driven by a pneumatic drive which needs 7 bars of pressurized air to move the applicator in the cell by $15 \mathrm{~mm} \mathrm{~s}^{-1}$. The deposited wet solvent-blend film can be dried in dry He- or $\mathrm{N}_{2}$-atmosphere. The gas flow could be driven into two tight washing bottles filled with solvent so that the solvent vapor pressure within the cell increases. That can be used eg. to slow down the drying process. The gas hoses and the washing bottles are very tight and immersed in the water that circulates through the cell walls and the heating stage. The cell atmosphere is therefore very well heat controlled. 


\section{WILEY-VCH}

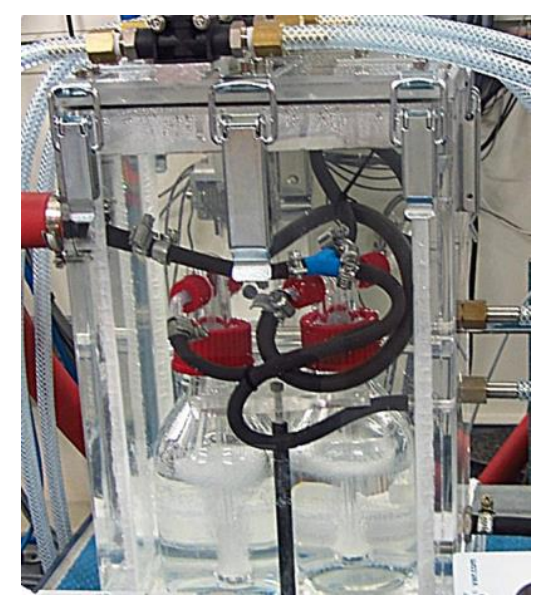

Figure S4. Very tight gas hoses and two washing bottles filled with the solvent (oDCB) are within a Plexiglas chamber. They are immersed in water circulation that flows through the walls of the sample cell and the copper heating plate.

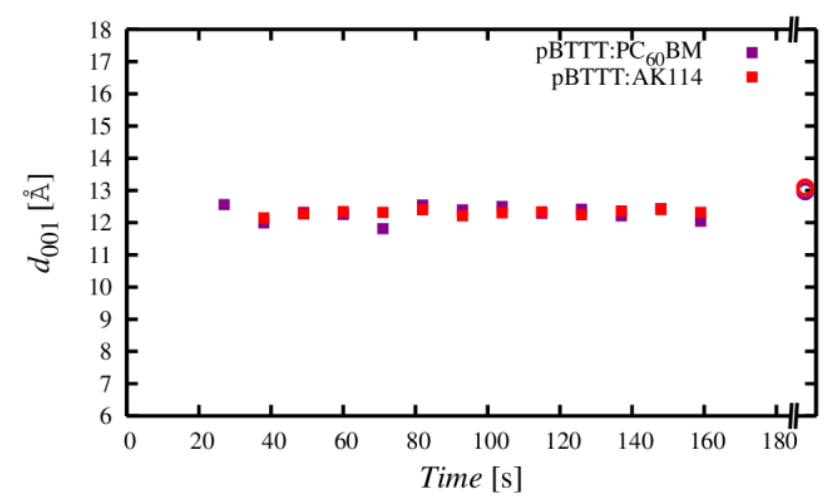

Figure S5. Temporal change of the $\mathrm{d}_{001}$ spacing of fullerene sub-lattice in the bimolecular crystal during drying as derived from the time resolved GIXD measurements. The open circles on the right axis represent the completely dried films measured in vacuum. 


\section{WILEY-VCH}

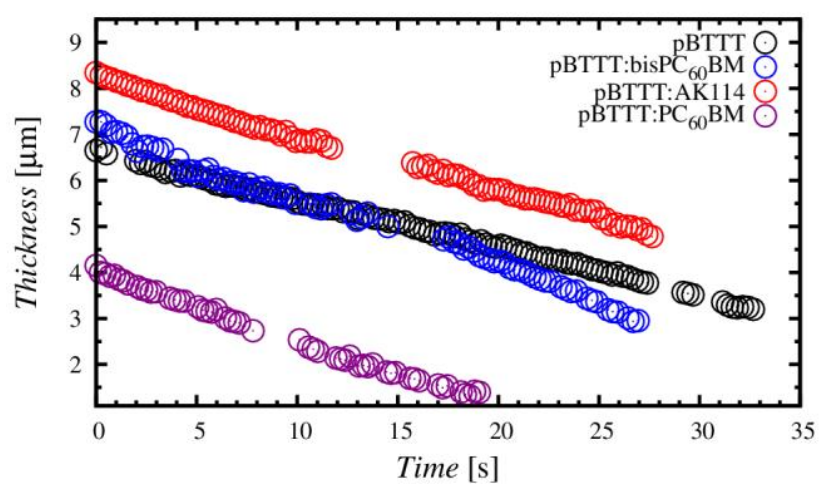

Figure S6. Thickness of the thin liquid films as a function of time upon drying. The thickness was calculated from the interference fringes of the reflectance spectra recorded during drying of the film.

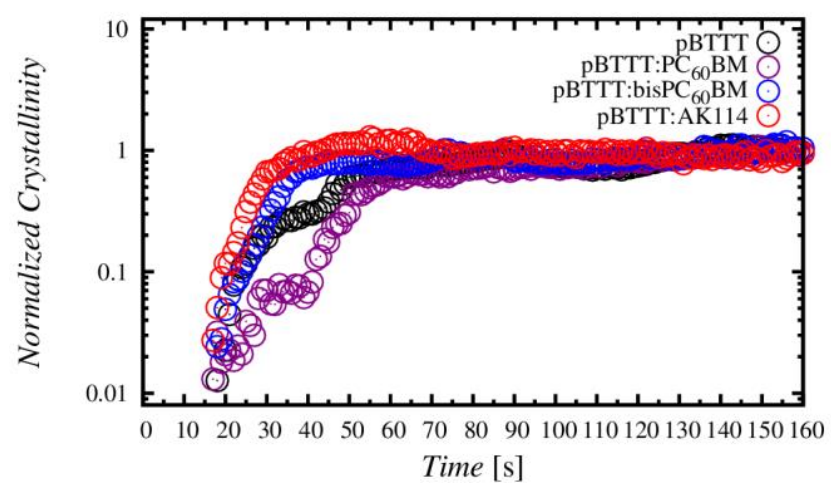

Figure S7. Normalized polymer crystallinity as a function of the drying time derived from the integrated intensity of the pBTTT (100) peak of real time GISAXS measurements.

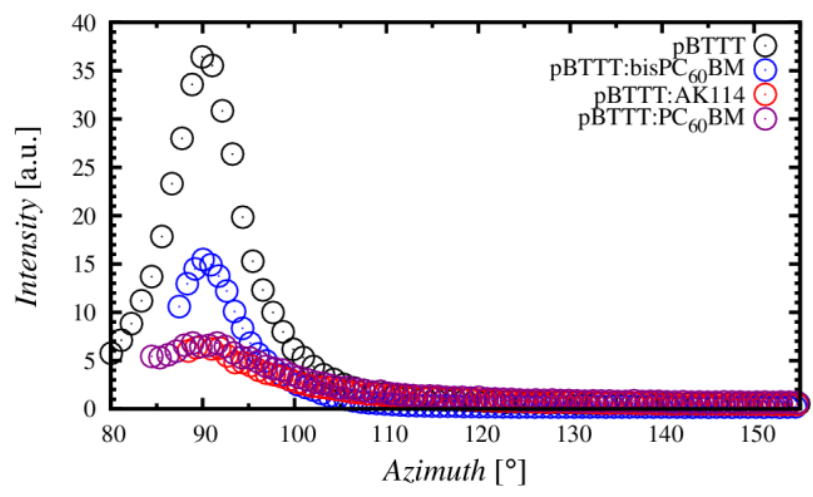

Figure S8. The azimuthal distribution of GIXD scattering intensity in the range of pBTTT (100) peak for the completely dried films. 


\section{WILEY-VCH}

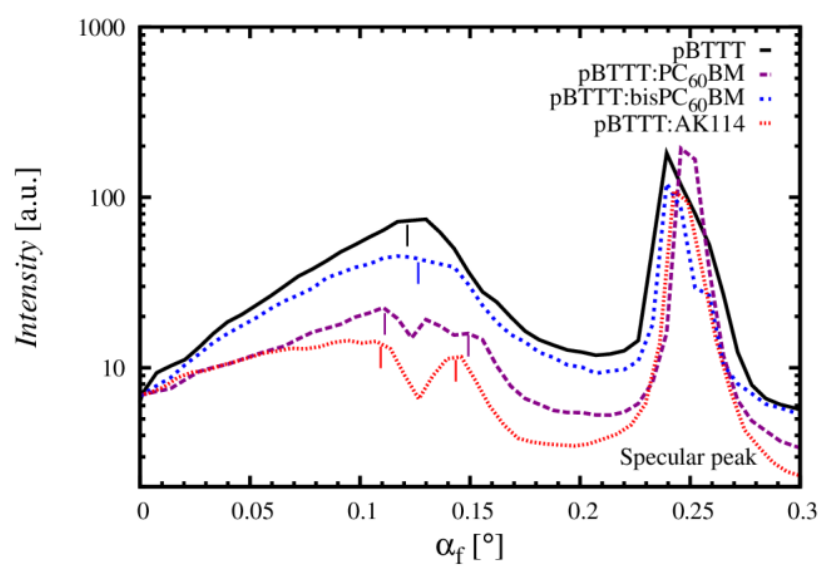

Figure S9. Yoneda and specular peaks at the slow drying stage (100 to $180 \mathrm{~s}$ ) in real time GISAXS measurements.

Critical angles at $10 \mathrm{KeV}$ (cf. Table S1) were determined using the refractive indices calculated from chemical formula and density via the website of the center for X-ray Optics. ${ }^{[1]}$

Table S1. Critical angles at $10 \mathrm{KeV}$ of the materials used in this work.

\begin{tabular}{ccccc}
\hline & $\delta$ & $\beta$ & SLD $\left[\AA^{-2}\right]$ & $\alpha_{c}\left[{ }^{\circ}\right]$ \\
\hline pBTTT-C16 $^{\circ}$ & $2.26000 \mathrm{E}-06$ & $9.96381 \mathrm{E}-09$ & $9.22577 \mathrm{E}-06$ & 0.122 \\
PC $_{60} \mathrm{BM}$ & $3.41864 \mathrm{E}-06$ & $3.66528 \mathrm{E}-09$ & $1.40000 \mathrm{E}-05$ & 0.150 \\
$\mathrm{Si}$ & $4.88890 \mathrm{E}-06$ & $7.35440 \mathrm{E}-08$ & $1.99471 \mathrm{E}-05$ & 0.179 \\
\hline
\end{tabular}

\section{References:}

[1] B. L. Henke, E. M. Gullikson, J. C. Davis, Atomic Data and Nuclear Data Tables 1993, $54,18$. 